\title{
Applying Six Sigma To Achieve Enterprise Sustainability: Preparations And Aftermath Of Six Sigma Projects
}

Abdullah AlSagheer, Hamdan Bin Mohammed e-University, Dubai, UAE

\begin{abstract}
Sustainability is not a method or a tool; it is the state of a company in which the efficiency of resources is maximized, customers are satisfied to a great extent, an improved condition is longlasting, success is maintained and competitive advantage is sustained. Literature review carried out in this research depicts that researchers have extensively worked on identifying and documenting the enablers, challenges, risks, projects, corporate commitments and strategic integration of Six Sigma with other frameworks. But at the same time, the literature establishes that Six Sigma is neither completely welcomed by companies nor the methodology has proven its worth for most of the corporations. The latter argument suggests the need for identification of gaps between the capabilities of Six Sigma methodology and the actual situation in the enterprise world. The theme of this paper is to explore the capabilities of Six Sigma that can enable companies to achieve the state of sustainability to a great extent. Three dimensions of Six Sigma are identified that includes strategic, tactical and operational dimensions. A 'Process Research and Development' model (PRAND) is presented at the end of paper with guidelines for future research.
\end{abstract}

Keywords: Sustainability; Benchmarking; Continuous Improvement; Six Sigma For Sustainability

\section{INTRODUCTION}<smiles>[C]1C=CCCC1</smiles>
ix Sigma is a scientific, systematic and statistical approach to business process improvement and is considered to be an important business strategy (Nakhai \& Neves, 2009). Six Sigma was developed by Motorola in 1980s as a methodology to improve manufacturing and quasi-manufacturing processes and settings (Nakhai \& Neves, 2009). The methodology targets the variation in processes, identifies and eliminates the defects or variations to improve quality and performance of business processes (Mortimer, 2006). The methodology employs sophisticated process analysis, data collection, quality management and control and statistical techniques in an integrated framework (Soti, Shankar \& Kaushal, 2010). The Six Sigma methodology requires a process to produce $99.99966 \%$ of the products or service units to be defect free which means that there can only be 3.4 defected units per million (Aboelmaged, 2010: McCarty \& Fisher, 2007). It will not be an overstatement to say that if all business processes produce $99.99966 \%$ accurate or desired products or services then the company will have higher customer satisfaction rate, higher profits, enhanced and improved business processes, better return on investments, satisfied stakeholders and a differentiated competitive advantage. But the real question will still remain at the same place i.e. 'How to make the effects long-lasting in order to achieve sustainability?' This research tends to answer this question in light of the extensive literature reviewed.

\section{DIFFERENT APPROACHES OF SIX SIGMA}

There are different phased approaches of Six Sigma when it comes to process improvement and root cause analysis (Raisinghani, Ette, Pierce, Cannon \& Daripaly, 2005). The widely used model of Six Sigma is a five phased framework that comprises of define, measure, analyze, improve and control (DMAIC) (Raisinghani, Ette, Pierce, Cannon \& Daripaly, 2005). In the defined (D) phase of this approach, the problem to be addressed is defined along 
with customer requirements, project scope and preliminary project plan (Raisinghani, Ette, Pierce, Cannon \& Daripaly, 2005). In the next phase of measure (M), data is collected and tools to be applied are identified (Raisinghani, Ette, Pierce, Cannon \& Daripaly, 2005). Root-cause analysis and establishing the relationships between different variables and causes are established using sophisticated statistical techniques in the analyze (A) phase of the Six Sigma lifecycle (Raisinghani, Ette, Pierce, Cannon \& Daripaly, 2005). Once the problem is identified, measured and analyzed, the experts design and implement a solution in the improve (I) phase. The last and most important phase of Six Sigma lifecycle that will have a focal importance in this research is the control (C) phase. Systematic and sophisticated strategic, statistical and scientific approaches are developed that tend to sustain the improved and implemented solution over a period of time (Raisinghani, Ette, Pierce, Cannon \& Daripaly, 2005). This phase is seen as a critical contribution of Six Sigma towards sustainability because defects once removed should not recur so that accuracy rate can be maintained over a longer period of time.

\section{LITERATURE REVIEW}

\section{Multidimensional View of Sustainability}

Sustainability is usually seen as a policy goal i.e. designing, developing and driving all the policy statements towards the achievement of sustainability (Bonn \& Fisher, 2008). If a company is achieving what it aimed for such as higher profits, higher customer satisfaction, least or zero defects, cost leadership, differentiated services and products, efficient manufacturing processes and highest quality standards; then the company is supposed to be in a successful sustainable state (Bonn \& Fisher, 2008). According to Thampapillai (2010), the state of sustainability of a company is driven by the market or industry in which the company operates. When a company operates in a market such as perfect competition, most of the operational and strategic initiatives of the company are driven by the competition (Thampapillai, 2010). This dependency on market forces is due to the comparison that a company conducts to review its services and processes with that of other companies in the market and hence strives for sustainability (Thampapillai, 2010).

A different concept of sustainability is presented by Stuteville \& Ikerd (2009) which states that sustainability can be achieved by continuous process and service learning mechanisms that aim at improvements, error removal and maintaining the error-free states. The future of economic development for any company depends on how willingly the company improves its processes, services and products and how effective are its policies in sustaining the improvements (Stuteville \& Ikerd, 2009). Onwueme \& Borsari (2007) views sustainability as a global issue and states that every company and human being have a "sustainability deficit" and therefore there is always a room for improvement. A company can achieve sustainability if and only if its employees and higher management are aware of what sustainability is and what the company goals are those would enable it to achieve the desired 'sustainability' (Onwueme \& Borsari, 2007). This relationship between awareness and achievement of sustainability can be further enhanced by proper and effective education of the employees across the hierarchy (Onwueme \& Borsari, 2007). Montgomery (2010) presents a modern framework to achieve enterprise excellence and sustainability. The recommended modern framework establishes the importance of three scientific and statistical tools and techniques. These tools include Six Sigma (DMAIC), design for Six Sigma and lean (Montgomery, 2010). Continuous improvement and sustainability can be achieved by incorporating quality/process improvement initiatives including the above three paradigms because enterprise excellence is subject to the excellence of each and every building block of the company whereas each building block comprises of business processes (Montgomery, 2010).

\section{Current State Of Management's Approach To Six Sigma}

An exploratory study in the form of panel discussion comprising leading practitioners, quality experts, general management and academicians was conducted by Antony (2007) to find out the real importance and applications of Six Sigma from a high level perspective and to demystify the related myths. The results of the study are quite interesting as it was revealed that not only Six Sigma practitioners but also other participants acknowledged the importance of defect removal from business processes to achieve business sustainability and continuous improvement whereas at the same time, the participants agreed that the Six Sigma methodology alone can not do miracles and must be integrated in the enterprise-wide picture (Antony, 2007). The participants also 
agreed to the fact that Six Sigma must be an enterprise-wide initiative and necessary training of employees on Six Sigma may enable the organization to achieve desired goals. In another important study by Kumar, Antony, Madu, Montgomery \& Park (2008), efforts were put in by the authors to demystify the common myths about Six Sigma and to explore the real potential of the methodology. The study was based on extensive literature review on the subject. The findings of the study neither favored the notion that Six Sigma is a "fad" nor the assumption that Six Sigma is an ordinary improvement methodology (Kumar, Antony, Madu, Montgomery \& Park, 2008).

To achieve the maximum advantages in the form of removed defects, continuous improvement and sustainability, Six Sigma needs to be integrated with other strategic frameworks that are targeted at achieving the corporate sustainability. It was found that the key to success with Six Sigma is to select the right project on right time because when an inappropriate Six Sigma project is picked up and fails, it has a negative effect on other ongoing Six Sigma projects (Kumar, Antony, Madu, Montgomery \& Park, 2008). Freisleben (2006) presented a basic "profit model for quality" and emphasized on the importance of communicating the Six Sigma benefits to top management. The microeconomic parameters selected for the model included price, unit costs, sales and fixed costs and correlation between price or microeconomic parameters and quality were tested. It was found that better quality yields better economic benefits to the company and thus the price and quality are positively correlated (Freisleben, 2006). This study shows that Six Sigma not only improves quality of processes and reduces cost but also enables the company to achieve sustainability through achieving a sustainable competitive advantage powered by cost leadership and differentiated services.

\section{An Integrated View Of Six Sigma}

In a study of 237 European firms conducted by Gutierrez, Montes \& Sanchez (2009), it was established that well planned, disciplined and managed Six Sigma teamwork integrated with other statistical process control techniques yielded extremely beneficial and positive results with respect to process and performance improvement. It was also established that proper impact of successful Six Sigma projects or initiatives positively affects the development of enterprise-wide shared vision and enables employees across the organizational hierarchy to work in the direction of achieving and maintaining sustainability (Gutierrez, Montes \& Sanchez, 2009). However organizational learning towards Six Sigma is an important aspect that should be incorporated in the overall organizational learning framework in order to maximize on the output of Six Sigma projects (Gutierrez, Montes \& Sanchez, 2009). Dynamic organizational learning has been found to be an important decisive factor in achieving the sustainability (Gutierrez, Montes \& Sanchez, 2009: Savolainen \& Haikonen, 2007). But incorporating six-sigma in organizational-learning for continuous improvement is still an evolving phenomenon because of the relativity of improvement issues that are industry or even company specific (Savolainen \& Haikonen, 2007). The improvements done to the processes by implementing Six Sigma must be incorporated in the learning process so that the employees and process owners can gauge their knowledge and experience about measurements, detection, correction and prevention of errors and cost reduction (Savolainen \& Haikonen, 2007).

\section{Lack Of Benchmarking with Six Sigma}

McCarty \& Fisher (2007) conducted a research to explore the 'tangible' benefits of Six Sigma implementation in a service-oriented sector. Multiple case-studies of cost reduction and performance improvement using Six Sigma were analyzed and the authors concluded that with appropriate and planned implementation, tangible results (cost reductions specifically) can be achieved (McCarty \& Fisher, 2007). The study also identified that lack of six-sigma-aligned benchmarking let the variations to recur and that if processes are standardized after Six Sigma implementation, sustainable improvement can be achieved (McCarty \& Fisher, 2007). There are two levels of benchmarking when it comes to Six Sigma methodology as identified in a research study conducted by (Miguel \& Andrietta, 2009). The first level complements the global Six Sigma benchmarks such as which tools should be used for which project, what type of analysis should be conducted, how the data should be collected, what should be the design of experiments and how the improvements should be controlled (Miguel \& Andrietta, 2009). The next level of benchmarking is relative to a specific Six Sigma project, company or process and is considered to be more important than the first level of benchmarking because it provides the relative standards of error identification, correction and prevention (Miguel \& Andrietta, 2009). This study too indicates the importance of 
learning from Six Sigma projects and to develop a continuous improvement strategy that should be well documented and well-communicated across the company.

\section{Dynamics Of Six Sigma Projects For Sustainability}

The importance of Six Sigma project selection has been widely researched and debated in the literature (Ray \& Das, 2010). If a right project is selected on the right time for the right purpose with right expectations, it will not be far from the truth that the results will be optimal and realistic as well (Ray \& Das, 2010). Many Six Sigma projects fail because either the wrong projects are identified or the problems to be solved are wrongly defined (Ray $\&$ Das, 2010). Therefore a mechanism should be developed to identify the appropriate projects. A study conducted by Breyfogle (2010) established certain success/failure parameters for a Six Sigma project such as alignment with business objectives and corporate strategy, customer requirements and needs, misidentification of defects or errors, abstract and high-level project scope and unclear project/goal statements. All the proposed Six Sigma projects should be documented at high-level and then ranked or prioritized according to their importance to the business (Breyfogle, 2010). A project priority index can be developed that may rank the projects according to their severity, need and benefit for the business; because there might be several Six Sigma projects in the pipeline and randomly selecting a project may result in the waste of efforts, time and money for the company (Breyfogle, 2010).

Commitment and input from top management are equally important decisive factors for the success of a Six Sigma project (Breyfogle, 2010). Another common pitfall in the selection of right Six Sigma projects is the fact that most of the projects result from a brain storming session which is usually held casually (Nakhai \& Neves, 2009). In order to have sustainable and long-lasting results from Six Sigma projects, it is important to have the Six Sigma project selection phase to be integrated with the overall business management program (Miguel \& Andrietta, 2009). These research efforts depict that the nature, complexity and relevance (co-alignment with business goals of the Six Sigma projects along with other strategic dimensions such as management's commitment determine the degree of success of the projects and their impact on the continuous improvement promise of the company. According to nonthaleerak \& Hendry (2008), there are two aspects of weaknesses or loopholes in Six Sigma methodology. First, appropriate tools are not selected for the right project and second the practitioners or implementers are either not true experts of Six Sigma or they have part time roles instead of full time roles. Six Sigma projects yield better results for high-risk large-scale projects that are better aligned with corporate policy as compared to the projects that are not aligned with company's goals and have low-risk indication with respect to the impact on overall functioning of the business (nonthaleerak \& Hendry, 2008).

\section{Challenges And Risks To be Monitored and Controlled}

In most of the cases, the challenges of Six Sigma in improving service performance and quality originate from the Six Sigma initiatives taken by the company (Nakhai \& Neves, 2009). The disoriented approach of Six Sigma champions and higher management in relentlessly selecting Six Sigma projects result in mere unrealistic expectations, limited applications and moderate benefits (Nakhai \& Neves, 2008). Whereas Six Sigma methodology is truly capable of achieving the expectations and targets of removing process defects and continuous improvement provided that the methodology is implemented in a knowledge-based environment (Thomas, Barton \& Byard, 2008). Integration of Six Sigma methodology and tools with other strategic and tactical approaches have been much debated in the literature. A study conducted by Ehie \& Sheu (2005) researched how the integration of Six Sigma with theory of constraints achieved desired results and bottom line performance. A continuous improvement project was selected based on the theory of constraints whereas Six Sigma provided several empirical and statistical techniques for defining, measuring, analyzing, controlling and improving the specific process (Ehie \& Sheu, 2005). The promising results of this study further establish the importance of a holistic approach towards continuous improvement and sustainability.

\section{METHODOLOGY}

This is a purely research paper that focuses on the qualitative literature comprising of scientific and published journals. Extensive review of literature has been carried out to explore the capabilities of Six Sigma for sustainability from several dimensions. The purpose of diverse and extensive review of literature for this research 
was to get an in-depth insight into the current state of research and knowledge with respect to the enterprise-wide applications of Six Sigma and to investigate further and integrate the findings of other scholars to form an holistic approach towards Six Sigma for sustainability. The criteria to select any literature or research composed of four essential parameters. Each and every research article was tested on the established criteria. First, the publication dates of the research papers were keenly observed as the nature of the topic requires insight into latest advancements with respect to Six Sigma and sustainability. Most of the literature reviewed for this research has been published in last three years. Second, the nature and reputation of journals in which the articles were published were observed. Articles from only well established journals such as International Journal of Lean Six Sigma, International Journal of Quality and Reliability Management and International Journal of Operations \& Production Management were selected. The third and most important parameter for the section of literature was the 'relevance to the theme'. The articles were screened for initial skimming and examination and only those papers were selected that focused on the enterprise-wide applications and implications of Six Sigma and those that focused on the holistic and integrated view of the Six Sigma paradigm in addition to the challenges, risks and enablers of the technology. The research papers that focused on the concept of sustainability have also been included and reviewed in the research. Fourth, the research type or methodology of the research papers was evaluated. Papers that researched case studies, conducted surveys and reviewed extensive scholarly work were selected for the paper. And finally the validity and diversity of findings of the research papers were analyzed. Research efforts that resulted in new and different findings from previous or other findings were given more weight in the final selection of the article for this research.

\section{Findings}

The critical review of all-embracing literature with respect to Six Sigma methodology and its decisive share in achieving sustainability was carried out in this research. The basic aim of the research was to understand and critically analyze the findings of scholarly research works and to develop a realistic framework that would enable the Six Sigma organizations to achieve sustainability. The study has found that there are ideally three dimensions of Six Sigma that need to be worked on i.e. strategic dimension, tactical dimension and operational dimension. This view can not only achieve desired results with Six Sigma but also may transform the Six Sigma methodology to a corporate strategy or philosophy. It is also observed from the literature review that no dimension of Six Sigma methodology can be preferred on other dimensions or ranked higher because every dimension shares a determinative role in achieving continuous improvement and sustainability. This is somehow true and realistic for a single or some Six Sigma projects but to achieve sustainability that is long-lasting and promises continuous improvement, it will be important to emphasize more on the strategic dimension followed by tactical dimension of the Six Sigma approach.

\section{Strategic Dimension}

There are certain key strategic drivers and enablers of successful implementation of Six Sigma. An effectual and decisive role from the top management is the most important enabler of Six Sigma success because the top-down approach will not only let the positive impact to trickle down to the bottom hierarchy and at the process level but will also create an environment for sustainability. It is also observed from the literature review that Six Sigma organizations lag behind in developing a shared vision of the methodology and expectations from it and therefore companies do not have a cohesive approach towards Six Sigma. There is another important aspect of organizational learning with respect to Six Sigma as witnessed in the literature. There should be a systematic and set mechanism to achieve maximum benefits from organizational learning. This learning and training will also include lessons learnt from Six Sigma projects (if any). On the other hand, development of Six Sigma culture seems to be more important than Six Sigma projects in an organization because such a culture will create a statistical thinking philosophy across the board that will not only enable the workforce to think in numbers but will also enhance their commitment and on-job learning. As far as the integration with other dimensions is concerned, the top strategic management should be involved in deciding the projects, prioritizing the projects and setting economic goals along with the process owners. It is equally important for the company to have a deep understanding of 'sustainability' just like the learning with Six Sigma because sustainable results can only be achieved when an integrated and cohesive approach is adopted with respect to training and learning. 


\section{The Tactical Dimension}

The tactical dimension of Six Sigma is equally important as the strategic dimension is because of its tendency to transform the shared vision of the company into reality. There are three aspects of tactical dimension as identified in the literature. First aspect is related to the dynamics of Six Sigma project selection. It has been found that the identification of problems and selection of right projects at right time are very important to reduce the variations and to achieve desired goals. Therefore a sound mechanism should be adopted to work on the exploration of projects and to create a project-pipeline (SSPPL). Second aspect is that of benchmarking the processes with Six Sigma results. Once a Six Sigma project is initiated and completed, the results should be made public to the company's employees and properly documented so that errors and defects do not recur in the future and the improvement can be made sustainable in the long-run. The third dimension is the continuous control and audit of PPL and benchmarking to ensure sustainable results with the Six Sigma methodology.

\section{The Operational Dimension}

Although operational dimension of Six Sigma has not been covered extensively in this research because of the proven and result-oriented tools and techniques that comprise the Six Sigma methodology, yet it can not be ignored. The DMAIC (Define, Measure, Analyze, Improve, Control) approach of Six Sigma was reviewed briefly in the introduction. There should be no problem in conducting the DMAI phases of the method however the 'Control ( C )' phase of Six Sigma will have definite impact on the sustainability of results because this phase maintains the mechanism of not only sustaining the results of Six Sigma projects but also ensures that the deviations and errors do not occur in future. Therefore emphasis should given to the 'Control' phase. All the results and control mechanisms should be properly documented followed by regular audit to ensure sustainability.

\section{CONCLUSION AND FUTURE RESEARCH}

There are several departments in an enterprise such as human resource department, production/manufacturing department, quality control, customer service, finance department, IT department etc. These departments comprise of business processes whereas every process produces some output when provided with desired inputs. These outputs can be accepted or rejected based on their quality. Therefore if these processes (building blocks) are refined and improved to be error free or to have least possible errors (as required by the standards of Six Sigma), then the entire corporation will have highest-quality mechanisms working in a cohesive manner and the company will be in a sustainable state provided that all other requirements of sustainability are met. However identifying, initiating, conducting, maintaining and sustaining Six Sigma projects and its results is a challenge for the organizations. The reasons for these challenges are multidimensional as identified in this research. These reasons include the commitment from management, the bottom-up and top-down communication mechanisms, unrealistic expectations, inappropriate resources, inappropriate projects and problem definitions and failure to sustain the results of a Six Sigma project. An integrated 'PRAND (Process Research And Development' model have been developed as a result of this research and it is proposed for any future researches on the subject to explore the model.

\section{The PRAND Model}

As described earlier, processes are the building blocks of any organization and if processes produce accurate and desired results over a longer period of time, the company will be in a sustainable state. However continuous and regular research and development may be needed for continuous improvement and sustainability with Six Sigma. Following figure shows the basic PRAND model and it is recommended for future research works to focus on the model and to expand it further. The idea is to have a specialized 'Process Research and Development' team or department in a company that will focus on identifying the potential process-improvement processes, maintain the documented improvements in processes for continuous learning and study the impact of Six Sigma projects on the enterprise sustainability. This proposal of having a dedicated research and development team is recommended for future research. 


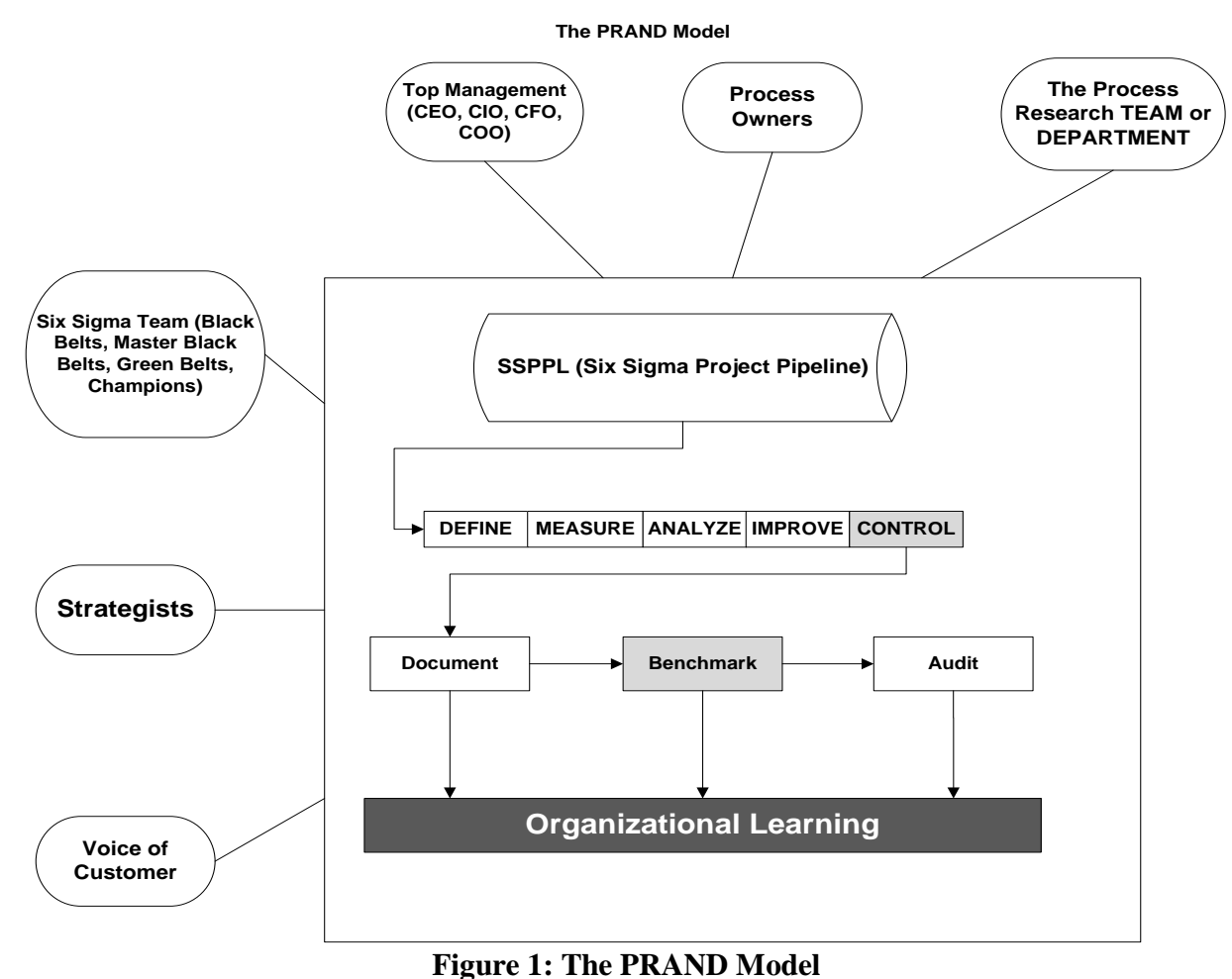

\section{AUTHOR INFORMATION}

Dr. Abdullah AlSagheer is an Assistant Professor of Management at the e-School of Quality and Business Management at the Hamdan Bin Mohammed e-University. He is teaching undergraduate courses level such as TQM Implementation, Capstone Project. In addition, he is teaching graduate courses level such as Strategic Management of Innovation and Technological change. Dr. AlSagheer has PhD in Education and Human Resource Studies specialized in Interdisciplinary Studies (Industrial and Human Recourse Management Engineering) and M.Ed Education and Human Resource Studies specialized in Interdisciplinary Studies (Industrial and Human Recourse Management Engineering) from Colorado State University (CSU). He received Master of Science in Electrical Engineering specialized in Integrated Systems \& Strategic Project Management. His undergraduate degrees were Bachelor of Science in Computer Engineering and a double major in Bachelor of Science in Electrical Engineering from California State University Long Beach (CSULB). Dr. AlSagheer research focuses in Strategic Management, Capstone Courses, Entrepreneurship and Leadership, Total Quality Management, Ergonomics and Human Factor Engineering, Curriculum Development, Human Resource Management, Management Training, Teamwork, Innovation Strategies. Engineering Management \& Industrial Engineering.

\section{REFERENCES}

1. Aboelmaged, M.G. 2010. 'Six Sigma quality: a structured review and implications for future research', International Journal of Quality \& Reliability Management, Vol 27 No 3, pp.268 - 317.

2. Antony, J.2007. 'Is six sigma a management fad or fact?, Journal of Assembly Automation, Vol 27 No 1, pp.17 - 19.

3. Bonn, I. \& Fisher, J. 2008. 'Sustainability: the missing ingredient in strategy', Journal of Business Strategy, Vol 32 No 1, pp.5 - 14

4. Breyfogle, F.W. 2010. Process improvement projects shortcomings and resolution', International Journal of Lean Six Sigma, Vol 1 No 2, pp.92 - 98.

5. Ehie, I. \& Sheu, C. 2005. 'Integrating six sigma and theory of constraints for continuous improvement: a case study', Journal of Manufacturing Technology Management, Vol 16 No 5, pp.542 - 553 
6. Freiesleben, J. 2006. 'Communicating six sigma's benefits to top management', Measuring Business Excellence, Vol 10 No 2, pp.19 - 27

7. Gutiérrez, L.G., Montes, F.J. \& Sanchez, O.B. .2009. 'Six sigma: from a goal-theoretic perspective to shared-vision development', International Journal of Operations \& Production Management, Vol. 29 No 2, pp.151 - 169

8. Kumar, M. Antony, J., Madu, C.M., Montgomery, D.C. \& Park, S.H. 2008. 'Common myths of Six Sigma demystified', International Journal of Quality \& Reliability Management, Vol. 25 No 8, pp.878 - 895.

9. McCarty, T.D. \& Fisher, S.A. 2007. 'Six sigma: it is not what you think', Journal of Corporate Real Estate, Vol 9 No 3, pp.187 - 196.

10. Miguel, P.A. \& Andrietta, J.M. 2009. 'Benchmarking Six Sigma application in Brazil: Best practices in the use of the methodology', Benchmarking: An International Journal, Vol. 16 No 1, pp.124 - 134

11. Montgomery, D.C. 2010. 'A modern framework for achieving enterprise excellence', International Journal of Lean SixSigma, Vol 1 No 1, pp.56-65.

12. Mortimer, A.L. 2006. 'Six sigma: effective handling of deep rooted quality problems', Assembly Automation, Vol 26 No 3, pp.200 - 204

13. Nakhai, B. \& Neves, J.S. 2009. 'The challenges of six sigma in improving service quality', International Journal of Quality \& Reliability Management, Vol 26 No 7, pp.663 - 684.

14. Nonthaleerak, P. \& Hendry, L. 2008. 'Exploring the six sigma phenomenon using multiple case study evidence', International Journal of Operations \& Production Management, Vol 28 No 3, pp.279 - 303.

15. Onwueme, I. \& Borsari, B. 2007. 'The sustainability asymptogram: A new philosophical framework for policy, outreach and education in sustainability', International Journal of Sustainability in Higher Education, Vol 8 No 1, pp.44 - 52

16. Raisinghani, M.S., Ette, H., Pierce, R., Cannon, G. \& Daripaly, P. 2005. 'Six Sigma: concepts, tools, and applications', Industrial Management \& Data Systems, Vol 105 No 4, pp.491 - 505

17. Ray, S. \& Das, P. 2010. 'Six Sigma project selection methodology', International Journal of Lean Six Sigma, Vol 1 No 4, pp.293 - 309.

18. Savolainen, T.Haikonen, A. 2007. 'Dynamics of organizational learning and continuous improvement in six sigma implementation', The TQM Magazine, Vol. 19 No 1, pp.6 - 17

19. Soti, A., Shankar, R. \& Kaushal, O.P. 2010. 'Modeling the enablers of Six Sigma using interpreting structural modeling', Journal of Modelling in Management, Vol. 5 No 2, pp.124 - 141.

20. Stuteville, R. \& Ikerd, J. 2009. 'Global sustainability and service-learning: paradigms for the future', International Journal of Organizational Analysis, Vol 17 No 1, pp.10 - 22

21. Thampapillai, D.J. 2010. 'Perfect competition and sustainability: a brief note', International Journal of Social Economics, Vol 37 No 5, pp.384 - 390

22. Thomas, A., Barton, R. \& Byard, P. 2008. 'Developing a Six Sigma maintenance model', Journal of Quality in Maintenance Engineering, Vol. 14 No 3, pp.262 - 271. 